\title{
Hemifacial Spasm: Results of Microvascular Relocation
}

\author{
David Fairholm, Jiunn-Ming Wu and Kan-Nan Liu
}

SUMMARY: Twenty patients with hemifacial spasm were treated between February 1980 and June 1981 . All presented with typical disabling unilateral contractions of the face. Computerized Tomographic Scan and angiograms ruled out structural mass lesions. All patients underwent posterior fossa microsurgical relocation of a vessel from the root entry zone of the facial nerve. An offending arterial loop was found in each case. Nineteen patients are free of symptoms and the remaining one is improved. One patient has permanent loss of hearing and two developed mild facial weakness. There has been no recurrence in 18 months follow up. These results give further support to the theory that hemifacial spasm is an affliction of the seventh nerve in the cerebello-pontine angle, most commonly caused by vascular cross compression at the root entry zone. Surgical relocation of the offending vessel relieves the symptoms and there appears to be no recurrence. This procedure is not difficult and carries acceptable risk for the patient with this disabling condition.

RÉSUMÉ: Nous avons traité vingt patients avec spasmes hémifaciaux de février 1980 à juin 1981 . Tous les patients présentaient des contractions unilatérales du visage. La tomodensitométrie et les angiogrammes éliminèrent des lésions structurales. Chez tous les patients nous avons, par microchirurgie de la fosse postérieure, déplacé un vaisseau situé à la racine d'entrée du nerf facial. Dans tous les cas nous avons trouvé une boucle artérielle impliquée dans la compression. Des 20 patients, 19 sont libres de symptômes et l'autre est amélioré. Un patient est sourd de façon permanente et deux patients ont développé une légère faiblesse faciale. Après 18 mois d'évolution il n'y a pas eu de reprise des symptômes. Ces résultats confirment le fait que le spasme hémifacial est causé par une lésion du 7e nerf qui est comprimé à sa racine, souvent par une malformation artérielle. Le traitement implique un déplacement du vaisseau coupable et semble s'accompagner d'une rémission permanente. Cette procédure n'est pas difficile et semble être d'un risque acceptable pour le patient ainsi affligé.

Can. J. Neurol. Sci. 1983; 10:187-191

Hemifacial spasm is a clinical syndrome characterized by paroxysmal, involuntary, unilateral, contraction of the facial muscles. It is progressive and may have disabling physiological, psychological, and social effects.

Gardner (1962) postulates that hemifacial spasm was caused by a compressive lesion of the seventh nerve in the cerebellopontine angle. Questions regarding etiology and concern about surgical risk have resulted in a variety of treatments. Jannetta (1977) reported that microvascular decompression of an aberrant vascular loop in the cerebello-pontine angle is effective in relieving the spasms. Accepting microvascular compression as the common etiology, we have used posterior fossa craniotomy and vascular relocation as the treatment of choice for this condition. This paper reports the experience in our first twenty patients.

\section{Clinical Material and Methods}

Between Feb. 1980 and June 1981, 20 patients with hemifacial spasm were treated. (Table 1) There were 11 males and 9 females with ages ranging from 26 to 60 years and a mean age of 47. The duration of symptoms was from 1 to 20 years. All were distressed with some degree of incapacity and most reported previous attempts at treatment including partial section of the facial nerve, thermodenervation, and drug therapy with phenytoin, carbamazepine, corticosteroids, and traditional Chinese herbal medicines. All had progressing facial spasms. Two patients had atypical symptoms. One had severe facial spasm on the left with mild hemifacial spasm on the right. The contractions were not synchronous. The other had had typical progressing hemifacial spasm for two years with three previous episodes of glossopharyngeal neuralgia. He had a one month history of continuing episodes of glossopharyngeal neuralgia, was unable to eat, and had become cachectic and emaciated. He responded initially to carbamazepine but later had no relief. Three patients complained of tinnitus with the spasms and two had ipsilateral lacrimation associated with spasms. Two patients complained of decreased hearing preoperatively and this was confirmed on auditory studies. One had bilateral decreased hearing and one had unilateral hearing loss on the ipsilateral side. One patient complained of numbness in the V2 distribution but had no facial pain.

Following clinical diagnosis all patients had posterior fossa angiography and some underwent CT Scanning. The angiographic findings were not specific and could not be correlated with the operative findings. At present only a contrast enhanced CT Scan to rule out compressive mass lesions is done. (A recent case revealed an epidermoid cyst).

From the Division of Neurosurgery, Department of Surgery, Chang Gung Memorial Hospital, Taipei, Tajwan.

Received July 29, 1982. Accepted for publication April 16, 1983.

Address reprint requests to Dr. David Fairholm, Chang Gung Memorial Hospital, 199, Tung Hwa North Road, Taipei, Taiwan. 


\section{Table 1: Twenty Patlents Treated by Microvascular Relocation}

\begin{tabular}{|c|c|c|c|c|c|}
\hline CASE NO & $A G E$ & DURATION & VESSEL & RESULT & REMARKS \\
\hline 1 & 55 & 2 yrs. & $* \mathrm{~V}$ & No spasm & \\
\hline 2 & 56 & 2 yrs. & $\mathbf{V}$ & No spasm & \\
\hline 3 & 30 & 6 yrs. & *AICA & $\begin{array}{l}\text { Mild spasms } \\
\text { persist. }\end{array}$ & $\begin{array}{l}\text { Postop. tinnitus } \\
\text { vesicular face eruption } \\
\text { temporary decreased } \\
\text { hearing. }\end{array}$ \\
\hline 4 & 52 & 2 yrs. & AICA & $\begin{array}{l}\text { Spasm } \\
\text { recurred } 10 \\
\text { days, re-op. } \\
\text { no spasm. }\end{array}$ & $\begin{array}{l}\text { At repeat } O p . \text { sponge } \\
\text { was slipped and was } \\
\text { relocated. }\end{array}$ \\
\hline 5 & 26 & 5 yrs. & AICA & No spasm & $\begin{array}{l}\text { Temporary decreased } \\
\text { hearing. }\end{array}$ \\
\hline 6 & 51 & 4 yrs. & $\mathbf{v}$ & No spasm & \\
\hline 7 & 38 & 6 yrs. & AICA & No spasm & Postop. tinnitus. \\
\hline 8 & 54 & 4 yrs. & V & No spasm & \\
\hline 9 & 40 & $20 \mathrm{yrs}$. & AICA & No spasm & \\
\hline 10 & 53 & 5 mos. & AICA & No spasm & $\begin{array}{l}\text { Preop. facial numbness. } \\
\text { Postop. developed pro- } \\
\text { gressing neurologic } \\
\text { signs with no cause } \\
\text { found. }\end{array}$ \\
\hline 11 & 59 & 2 yrs. & AICA & No spasm & $\begin{array}{l}\text { Temporary facial } \\
\text { weakness. Temporary } \\
\text { decreased hearing. }\end{array}$ \\
\hline 12 & 56 & 2 yrs. & $\mathbf{V}$ & No spasm & Postop. hiccups. Deaf. \\
\hline 13 & 58 & $11 / 2$ yrs. & AICA & No spasm & Mild facial weakness. \\
\hline 14 & 54 & 20 yrs. & V & No spasm & \\
\hline 15 & 60 & $1 \mathrm{yr}$ & AICA & No spasm & \\
\hline 16 & 37 & 3 yrs. & AICA & $\begin{array}{l}\text { Persistent } \\
\text { spasm re-op. } \\
\text { - no spasm. }\end{array}$ & $\begin{array}{l}\text { At repeat operation } \\
\text { another vessel found. }\end{array}$ \\
\hline 17 & 54 & 4 yrs. & AICA & No spasm & \\
\hline 18 & 40 & 6 yrs. & AICA & No spasm & \\
\hline 19 & 52 & 3 yrs. & *PICA & No spasm & $\begin{array}{l}\text { Associated with glosso- } \\
\text { pharyngeal neuralgia } \\
\text { preop. }\end{array}$ \\
\hline 20 & 38 & 4 yrs. & $\mathbf{V}$ & No spasm & Postop. tinnitus. \\
\hline
\end{tabular}

*AICA - Arterior Inferior Cerebellar Artery.

$*$ V - Vertebral Artery.

*PICA - Posterior Inferior Cerebellar Artery.

\section{TreatMENT AND RESULTS}

All patients underwent a posterior fossa procedure with unilateral craniectomy as described by Jannetta (1977). A small retromastoid suboccipital skin incision was made and a small craniotomy was done. The lateral sinus was exposed, the dura was opened, and the cerebellum elevated. Relaxation was achieved by controlled respirations and drainage of cerebral spinal fluid from the cisterns. The 7 th and 8 th cranial nerves were identified and the root entry zone exposed by elevation of the flocculus and choroid plexus in the region of the foramen of Luschka. In each case an arterial loop was found compressing the facial nerve at the root entry zone (Fig. 1). The artery curved upwards as a loop, usually the main stem or a branch of the anterior inferior cerebellar artery (AICA) and was usually nestled anterior and slightly caudal under the root entry zone. The brain stem was often grooved by the vessel. The AICA or its branches were involved in 12 cases, the vertebral artery in 7 and the posterior inferior cerebellar artery (PICA) in one (Table 1). The patient with glossopharyngeal neuralgia had a large redundant PICA which lay close to the medulla under the root entry zone of the 9th and 10th nerves and looped upwards on to the root entry zone of the 7th nerve. In all cases, the offending vessel was relocated away from the root entry zone and held by a notched Teflon sponge.

Sixteen patients had immediate postoperative relief of their spasm. The patient with glossopharyngeal neuralgia was relieved of both pain and spasms. One patient's spasms resolved over three weeks, and two patients underwent re-exploration for persistent spasms. In one case the sponge had slipped, the vessel was relocated and the sponge repositioned. In the other case, at reoperation, a branch of AICA which was not recognized the first time, was seen to be nestled in the entry zone of the 7 th nerve and this was relocated. Recovery was complete in both of these patients. The 4 th patient has decreased but persistent spasms and has refused re-exploration. Four patients had decreased hearing postoperatively; three have recovered and auditory evoked potentials show only pro-
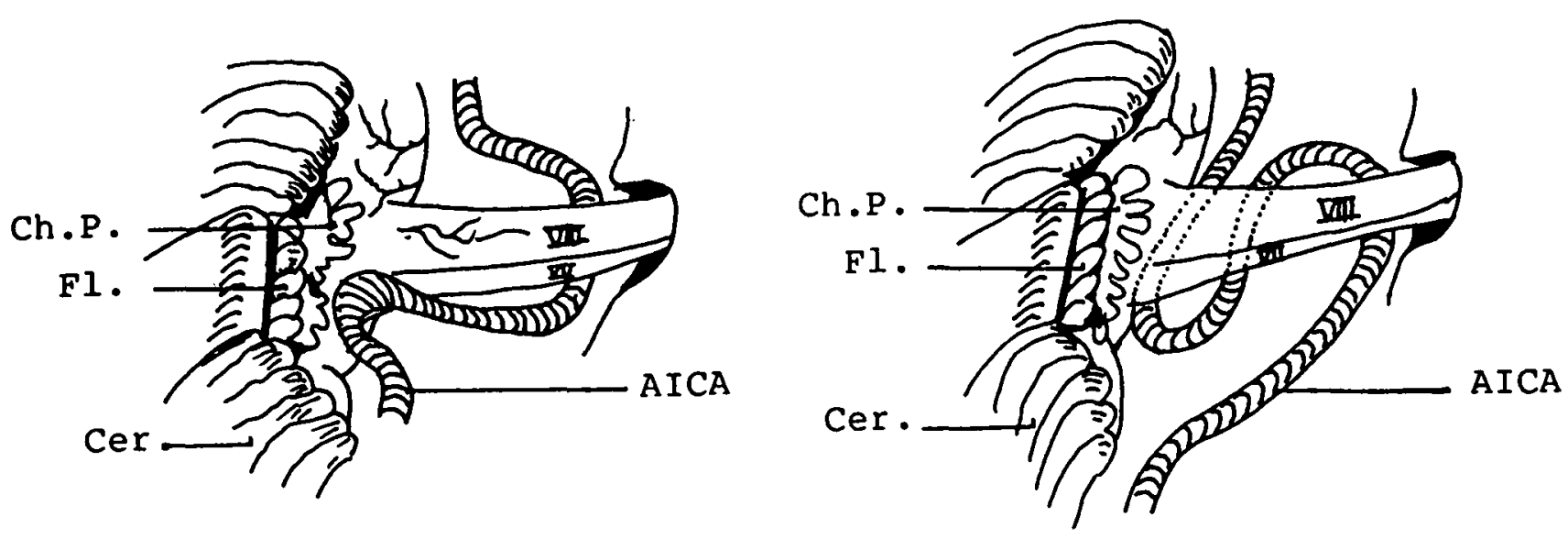

Figure I-Schematic drawing to represent the position of AICA on the seventh nerve. Code: VII, Seventh Nerve; VIII, Eighth nerve; AICA, Anterior Inferior Cerebellar Artery; Ch.P, Choroid Plexus; F1, Flocculus; Cer, Cerebellum. 
longed latencies. One patient has persistent unilateral hearing loss. Three patients had transient increase in tinnitus, one had a Herpes like vesicular eruption on the lower face and two patients had mild transient facial weakness. All patients have now been followed for a minimum of 18 months and there has been no recurrence of spasms.

\section{Discussion}

\section{Historical Review}

Hemifacial spasm was first identified as a syndrome by Gowers (1888) and the first accurate clinical descriptions were given by Brissaud (1894) and Babinski (1905). A thorough review of the clinical picture was provided by Ehni \& Woltman (1945). The long controversy over etiology has led to a wide variety of treatments. Hunt (1909) suggested that hemifacial spasm resulted from irritation of the sensory portion of 7 th nerve. Cushing (1917), Dandy (1934), and Campbell (1947) have reported hemifacial spasm in association with mass lesions and cirsoid aneurysms of the basilar artery. Woltman et al. (1951) reported results of decompression of the facial nerve in the bony canal. Cawthorne (1956) noted that neurolysis, contusion, and even division of the nerve in the Fallopian canal led to paralysis, but with recovery of function, there was a recurrence of the spasms. Bragdon (1960) crushed the facial nerve with a hemostat in the cerebello-pontine angle and others have directed a high force jet of saline on the nerve to separate and injure fibers. Alcohol (Harris, 1932; Seidman, 1980), and phenol injections (Toremalm, 1977), radio frequency lesions (Kao, 1978) and sectioning have been attempted at or distal to the stylomastoid foramen. Peripheral nerve crushes, complete or differential nerve sectioning and thermocoagulation (Scoville, 1955; Nosik \& Weil, 1956; Scoville, 1969; Miehlke, 1981) showed decreased spasm with weakness but as the nerve recovers, spasms recur with decreased intensity. Facial-hypoglossal anastomosis initially recommended by Harris (1932) gives permanent relief of the spasms but resultant facial function is never normal. The use of a wide variety of medication has been disappointing although in selected cases, carbamazepine may help. Alexander (1982) reports three cases and reviews another 46 in which carbamazepine has been effective treatment in more than 50 percent of cases.

Gardner was the first to carry out decompression of the facial nerve in the cerebello-pontine angle. (Gardner and Sava, 1962; Gardner, 1962; Gardner, 1966). Since then others (Neagoy \& Dohn, 1974; Jannetta, 1976; Jannetta et al., 1977; Maroon, 1978; Rhoton, 1978; Jannetta, 1979; Wilson, 1980; Liu et al., 1981, Auger, 1981; Samii, 1981; Yeh et al., 1982) have reported favourable results with decompression of the facial nerve in the cerebellopontine angle at the root entry zone.

\section{Diagnosis}

The differential diagnosis of hemifacial spasm includes other facial movements disorders such as facial myokymia, blepharospasms, aberrant regeneration of the facial nerve following Bell's palsy, and focal motor seizures. The diagnosis is based on the clinical history of progressive, involuntary, unilateral, spasmodic contraction of the facial muscles and the typical features noted on physical examination. Although Kondo et al. (1981) found angiography valuable, we have not found any consistent abnormalities (Liu, 1982) and have abandoned the procedure. Our investigation is now limited to preoperative CT
Scan to rule out compressive mass lesions. Sobel (1980) has adopted a similar approach after studying 24 patients.

\section{Pathogenesis}

Many theories have been proposed to explain hemifacial spasm but none have been widely accepted (Morley 1976). It is not likely due to a supranuclear abnormality since it is unaffected by stroke or hemispheral lesions. It has been attributed to pathological processes within the brain stem causing irritation of the facial nucleus or nerve. Ferguson (1978) suggests that after nerve injury, axonal sprouting of afferent fibers or increased recurrent collaterals causes increased dendritic activity. This results in changing central control and is the basis for hyperexcitability and re-organization of the nucleus with self-exciting activity. However Magun and Esslen (1959) reported extensive electromyographic studies and concluded that hemifacial spasm can only be produced by alterations in a section of the nerve peripheral to the neuron. Recently Auger (1981) reported results of electrophysiologic testing in eight patients undergoing surgery. Synkinesis disappeared postoperatively and he suggests that the abnormality responsible for hemifacial spasm must be in the extra-axial portion of the nerve.

Early reports suggested involvement in the mastoid section of the nerve due to edema, constriction, or fibrosis. However, Woltman et al. (1951) report only $20 \%$ improvement following facial nerve decompression in the petrous bone. Careful neurolysis does not effect a cure. Contusion of the nerve or sectioning in the Fallopian canal may relieve the spasms but they recur with recovery of nerve function (Cawthorne, 1956). Toremalm (1977) reported 6 cases treated by intraosseal exposure of the facial nerve. All patients had facial paresis and spasms recurred after recovery of the paresis. Section of the nerve distal to the stylomastoid foramen effectively stops the spasms. All this evidence indicates that the lesion is proximal to the stylomastoid foramen or the mastoid canal.

Many authors have reported the association of hemifacial spasm and compressive lesions in the cerebello-pontine angle (Cushing, 1917; Dandy, 1934; Ehni, 1945; Campbell, 1947; Gardner, 1962; Fabinyi, 1978; Davis, 1981). Similarily Maroon (1978), Pierry (1979), Shih (1981 - personal communication), and Dujovny (1979) have indicated large arterio-venous malformations or aneurysms are associated with hemifacial spasm. Subsequent to our initial series, we have had one case caused by an epidermoid cyst in the CP angle. Gardner and Sava (1962) were the first to report a significant number of surgical cases where the 7th nerve was compressed by an obvious pathologic process or a redundant vessel in the cerebellopontine angle. Seven of eighteen cases clearly had a mass lesions (aneurysm or AV malformation), 7 were compressed by a redundant AICA and 5 cases showed no apparent involvement of the 7 th nerve. They suggested that hemifacial spasm is the expression of a reversible pathophysiologic state commonly produced by mild long standing compression of the 7 th nerve in the cerebello-pontine angle. Jannetta $(1976,1977$, $1979,1981)$ believes that hemifacial spasm is caused by vascular loop compression of the 7th nerve at the root entry zone. He has recently reported 229 cases in which microvascular decompression of the nerve results in relief of spasms in $93 \%$ of cases (Jannetta, 1981). The vessels implicated are tortuous or redundant loops of the basilar, vertebral, anterior inferior cerebellar and posterior inferior cerebellar arteries. 
Jannetta's conclusion regarding etiology has been supported by others (Neagoy, 1974; Maroon, 1978; Rand, 1981; Rushworth, 1982). Iwakuma (1982) compares the results of treatment with three surgical procedures and shows the superiority of microvascular decompression. On the other hand, Fabinyi (1978), Kaye (1981), and Auger (1981) feel that relief of spasms may not be related to decompression but due to mild trauma and subsequent circumferential fibrosis of the nerve although they present no pathologic studies.

Electrophysiologic studies have been done by Auger (1979) using supraorbital nerve stimulation. A normal response is a simple contraction of the orbicularis oculi muscle. However in hemifacial spasm, stimulation causes a marked synkinetic contraction of other facial muscles. In 23 cases studied, this response was present in all patients on the affected side but in no patient on the unaffected, normal side. This suggests a short circuiting of the efferent stimulus with transaxonal transmission and efferent discharges in out going axons. There were no EMG changes or fibrillation potentials. The only other condition which will mimic this is aberrant regeneration of the 7th nerve. However careful history and EMG studies will differentiate this disorder. Moller (1982) found a prolonged latency of Peak V in brain stem auditory evoked potentials in patients with hemifacial spasm and suggests that the same vascular compression which affects the seventh nerve often affects the auditory system.

Pathologic studies have shown that myelin degenerates with age and is more vulnerable to mechanical pressure. It is well recognized that a peripheral nerve is most vulnerable at the root entry zone, where a thin glial sheath is replaced by the thicker and more protective schwann cell sheaths. Ruby and Jannetta (1975) studied biopsies of the facial nerve taken at the time of surgery and demonstrated hypomyelination of many of the myelin sheaths with disorganization of myelin lamellar structures. In more advanced cases, myelin was broken down or was a disorganized mass. Axis cylinders were eccentrically placed or were totally denuded and hypertrophic suggesting early microneuroma formation. In a post mortem case Iwakuma (1982) found proliferation of Schwann cells and fascicular demyelination at the nerve root suggesting chronic compression. Thus the clinical, experimental, electrophysiologic, and pathologic evidence supports the theory that hemifacial spasm is an affliction of the facial nerve in the cerebello-pontine angle. Although the nature of this disorder is not certain, there is increasing evidence for an association with compression at the proximal segment of the nerve, most commonly by a vascular loop.

Our experience provides further evidence that aberrant vascular loops are often found compressing the root entry zone of the seventh nerve in patients with hemifacial spasm. Relocation of the vascular loops results in relief of the spasm. The surgical procedure as described by Jannetta (1977) is not difficult but requires care in patient positioning, in elevation of the cerebellum, in accurately retracting the flocculus and choroid plexus to identify the root entry zone, and in preserving the small perforating branches going into the brain stem which are sometimes stretched by retraction and relocation of the offending vascular loop. A posterior fossa craniotomy carries the risks of any major intracranial procedure, but with modern anesthesia and microsurgical techniques these risks can be reduced to an acceptable level.
Although our follow up is so far only $\mathbf{1 8}$ months, there has been no significant recurrence.

\section{REFERENCES}

Alexander, G.E. and Moses H. III (1982). Carbamazepine for hemifacial spasm. Neurology 32:286-287.

Auger, R.G. (1979). Hemifacial spasm: Clinical and Electrophysiologic observations. Neurology 29:1261-1272.

Auger, R.G., Peipgras, D.G., Laws, E.R., et al. (1981). Microvascular decompression of the facial nerve for hemifacial spasm: Clinical and electrophysiologic observations. Neurology 31:346-350.

Babinski, J. (1905). Hemispasme facial peripherique. Rev. Neurol. 13:443-450.

Bragdon, F.H. (1960). Intracranial crushing of the facial nerve for hemifacial spasm. Presented at the Congress of the American College of Surgeons.

Brissaud, E. (1894). Tics et spasmes cloniques de la face. J. Med. Chir. Pract. 65:49-64.

Campbell, E. and Keedy, C. (1947). Hemifacial spasm: A note on the etiology in two cases. J. Neurosurg. 4:342-347.

Cawthome, T. (1956). Facial Palsy. Br. Med. J. 11:1197-1200.

Cushing, $H$. (1917). Tumors of the nervus acusticus and the syndrome of the cerebello-pontine angle. WB Saunders Co., Philadelphia.

Dandy, W.E. (1934). Concerning the cause of trigeminal neuralgia. Am. J. Surg. 23:447-455.

Dandy, W.E. (1945). Surgery of the brain. In: Lewis's practice of surgery, Vol. 12, WF Prior Co., Hagerstown, M.D.

Davis, W.E., Luterman, B.F. et al. (1981). Hemifacial spasm caused by cholesteatoma. Am. J. Otol. 2:272-273.

Dujovny, M., Osgood, C.P., Faille; R. et al. (1979). Posterior fossa AVM producing hemifacial spasm. Angiology 30:425-432.

Ehni, G. and Woltman, H.W. (1945). Hemifacial spasm: Review of one hundred and six cases. Arch. Neurol. Psychiatry 53:205-211.

Fabinyi, G.C.A. and Adams C.B.T. (1978). Hemifacial spasm: Treatment by posterior fossa surgery. J. Neurol. Neurosurg. Psychiatry 41:829-833.

Ferguson, J.H. (1978), Hemifacial spasm and the facial nucleus. Ann. Neurol. 4:97-103.

Gardner, W.J. and Sava, G.A. (1962). Hemifacial spasm: A reversible pathophysiologic state. J. Neurosurg. 19:240-247.

Gardner, W.J. (1962). Concerning the mechanism of trigeminal neuralgia and hemifacial spasm. J. Neurosurg. 19:947-957.

Gardner, W.J. (1966). Cross talk - the paradoxical transmission of a nerve impulse. Arch. Neurol. 14:149-156.

Gowers, W.R. (1888). A manual of diseases of the nervous system. Vol. 11, London, J. and A. Churchill pp:228-237.

Harris, W. and Wright, A.D. (1932). Treatment of clonic facial spasm: a) by alcohol injection. b) by nerve anastomosis. Lancet 1:657-662.

Hunt, J.R. (1909). The sensory system of the facial nerve and its symptomatology. J. Nerv. and Ment. Dis. 36:321-350.

Iwakuma, T., Matsumoto, A. and Nakamura, N. (1982). Hemifacial spasm: Comparison of three different operative procedures in 110 patients. J. Neurosurg. 57:753-756.

Jannetta, P.J. (1976). Vascular compression of the facial nerve at the brain stem in hemifacial spasm: Treatment by microsurgical decompression. In Morley TP (ed.): Current Controversies in Neurosurgery, pp:435-442. WB Saunders Co., Philadelphia.

Jannetta, P.J., Abbasy, M., et al. (1977). Etiology and definitive microsurgical treatment of hemifacial spasm: Operative techniques and results in 47 patients. J. Neurosurg. 47:321-328.

Jannetta, P.J. (1979). Microsurgery of cranial nerve cross compression. Clinical Neurosurg. 26:605-607. 
Jannetta, P.J. (1981). Hemifacial spasm. In: The Cranial Nerves, edited by Samii, M. and Jannetta, P.J. Springer-Verlag Berlin, New York. pp:484-493.

Kao, M.C., Hung, C.C., Chen, R.C. and Lien, I.N. (1978). Controlled thermodenervation of the facial nerve in the treatment of hemifacial spasm. J. Formosan Med. Assoc. 77:226-233.

Kaye, A.H. and Adams, C.B. (1981). Hemifacial spasm: a long term follow up of patients treated by posterior fossa surgery and facial nerve wrapping. J. Neurol. Neurosurg. Psychiatry 44:1100-1103.

Kondo, A., Ishikawa, J.-I., et al. (1981). The pathogenesis of hemifacial spasm: Characteristic changes of vasculatures in Vertebro-basilar artery system. In: The Cranial Nerves, edited by Samii M. and Jannetta, P.J. Springer-Verlag Berlin, New York. pp:494-501.

Liu, K.N., Wu, J.M. and Fairholm, D.J. (1981). Hemifacial spasm: Treatment by posterior fossa surgery. J. Form. Med. Assoc. 80(11):1235-1239.

Liu, K.N. and Wu, J.M. (1982). Angiographic findings in hemifacial spasm. (In press).

Magun, R. and Esslen, E. (1959). Electromyographic study of reinnervated muscle and of hemifacial spasm. Am. J. Phys. Med. 38:79-86.

Maroon, J.C. (1978). Hemifacial spasm: A vascular cause. Arch. Neurol. 35:481.

Maroon, J.C., Lunsford, L.D. and Deeb, Z.L. (1978). Hemifacial spasm due to aneurysmal compression of the facial nerve. Arch. Neurol. 35:545-546.

Miehlke, A. (1981). Management of hemifacial spasm. In: The Cranial Nerves, edited by Samii, M. and Jannetta P.J. Springer-Verlag Berlin, New York. pp:478-483.

Moller, M.B., Moller, A.R. and Jannetta, P.J. (1982). Brain stem auditory evoked potentials in patients with hemifacial spasm. Laryngoscope 92:848-852.

Morley, T.P. (1976). Hemifacial spasm alias facial myokymia cause and treatment. In: Current Controversies in Neurosurgery, edited by Morely T.P. WB Saunders Co., Toronto. pp:431-434.

Neagoy, D.R. and Dohn, D.F. (1974). Hemifacial spasm secondary to vascular compression of the facial nerve. Cleve. Clin. Q.41:205-214.

Nosik, W.A. and Weil, A.A. (1956). Selective partial neurectomy in hemifacial spasm and the electrophysiologic selection of patients. J. Neurosurg. 13:596-602.
Pierry, A. and Cameron, M. (1979). Clonic hemifacial spasm from posterior fossa arteriovenous malformation. J. Neurol. Neurosurg. Psychiatry 42:670-672.

Rand, R.W. (1982). Gardner's neurovascular decompression for hemifacial spasm. Arch. Neurol. 39:510-511.

Rhoton, A.L. Jr. (1978). Microsurgical neurovascular decompression for trigeminal neuralgia and hemifacial spasm. J. Fla. Med. Assoc. 65:425-428.

Ruby, J.R. and Jannetta, P.J. (1975). Hemifacial spasm: Ultrastructural changes in the facial nerve induced by neurovascular compression. Surg. Neurol. 4:369-370.

Rushworth, R.G. and Smith, S.F. (1982). Trigeminal neuralgia. and hemifacial spasm: Treatment by microvascular decompression. Med. J Aust. 1(10):424-426.

Samii, M. (1981). Surgical treatment of hemifacial spasm. In: The Cranial Nerves, edited by Samii M. and Jannetta, P.J. SpringerVerlag Berlin, New York. pp:502-504.

Scoville, W.B. (1955). Partial section of proximal seventh nerve trunk for facial spasm. Surg. Gynec. Obstet. 101:495.

Scoville, W.B. (1969). Partial extracranial section of the seventh nerve for hemifacial spasm. J. Neurosurg. 31:106-108.

Seidman, M.S. and Vacharat, N. (1980). Idiopathic hemifacial spasm treated wtih alcohol injection: a case report. Ophthalmic Surg. 11:109-111.

Sobel, D., Nouman, D. Yorke, C.H. and Newton, T.H. (1980). Radiography of trigeminal neuralgia and hemifacial spasm. Am. J.R. 135:93-95.

Toremalm, N.G. et al. (1977). Hemifacial spasm. Nerve block with phenol under electromyographic control. Acta. Otolaryngol. 83:341-348.

Wilson, C.B., Yorke, C. and Priolean, G. (1980). Microsurgical vascular decompression for trigeminal neuralgia and hemifacial spasm. West. J. Med. 132:481-487.

Woltman, H.W., Williams, H.L. and Lambert, E.H. (1951). An attempt to relieve hemifacial spasm by neurolysis of the facial nerves. Proc. Mayo. Clinic 26:236-240.

Yeh, H.S., Tew, J.M. and Ramirez, R.M. (1981). Microsurgical treatment of intractable hemifacial spasm. Neurosurg. 9:383-386. 